\title{
MOBILIDADE URBANA: UMA ANÁLISE DOS PROBLEMAS DE INFRAESTRUTURA NA AVENIDA JOÃO MEDEIROS FILHO EM NATAL-RN
}

\author{
A. F. SANTOS JUNIOR* e G. G. NASCIMENTO \\ Instituto Federal de Educação, Ciência e Tecnologia do Rio Grande do Norte \\ antoniojunior_rn@yahoo.com.br ${ }^{*}$
}

Artigo submetido em junho/2016 e aceito em junho/2016

DOI: 10.15628/geoconexoes.2016.4716

\section{RESUMO}

$\mathrm{Na}$ atualidade a mobilidade urbana se apresenta como um dos principais desafios das cidades que apresentam um considerável crescimento demográfico, o planejamento urbano por sua vez é peça chave do poder público para que seja oferecida uma mobilidade urbana de qualidade a população nas médias e grandes cidades no Brasil. Este trabalho analisa a questão da mobilidade urbana na Avenida Dr. João Medeiros Filho na Zona Norte de Natal uma vez que esta vem se tornando a cada dia um problema no que se refere à questão da mobilidade, principalmente para os moradores dessa área da cidade. Enquanto procedimentos metodológicos utilizamos pesquisa bibliográfica pertinente ao tema abordado, entrevistas formais, consultas a órgãos públicos de nosso interesse bem como trabalho in locus. Concluímos que a avenida ao longo do tempo se tornou uma das principais não só da Zona Norte, mas da cidade como um todo. Ressaltamos ainda que se faz urgente um processo de transformação nesta uma vez que o fluxo nessa área é crescente e sua infraestrutura não vem acompanhando a contento a dinâmica de mobilidade nesta área da cidade, fato que tem trazido consequências negativas à população ali residente e/ou que a utiliza em seu cotidiano.

PALAVRAS-CHAVE: Produção/Reprodução do Espaço. Mobilidade Urbana. Avenida João Medeiros Filho.

\section{URBAN MOBILITY: AN ANALYSIS OF INFRASTRUCTURE PROBLEMS IN THE JOÃO MEDEIROS FILHO AVENUE IN NATAL-RN}

\begin{abstract}
At present urban mobility is presented as one of the main challenges of the cities with a considerable population growth, urban planning in turn is a key part of the government to be offered an urban mobility quality population in medium and large cities in Brazil. This paper analyzes the issue of urban mobility in João Medeiros Avenue Son in the North Zone Natal city since this is becoming every day a problem with regard to the issue of mobility, especially for the residents of this city area. While methodological procedures use relevant literature to the topic discussed, formal interviews, consultations
\end{abstract}

with public agencies of our interest and work in locus. We conclude that the avenue over time has become one of the leading not only the North Zone, but also the city as a whole. We also emphasize that it is urgent a process of transformation in this since the flow in that area is growing and its infrastructure is not keeping up with satisfaction the dynamics of mobility in this area of the city, a fact that has brought negative consequences to their resident population and / or which uses it in their daily lives.

KEYWORDS: Production / Play Space. Urban Mobility. João Medeiros Filho Avenue. 


\section{INTRODUÇÃO}

A descrição do espaço é uma importante característica da ciência geográfica, descrever a Zona Norte de Natal área de estudo deste trabalho e mais precisamente a Avenida Doutor João Medeiros Filho, objeto de estudo do mesmo, é apontar que o espaço geográfico está em constante movimento e que este movimento possibilita o surgimento de característica nem sempre positivas no espaço e são justamente essas características negativas e positivas que fazem com que o espaço geográfico seja algo discutível. Estudar e trabalhar são atividades desafiadoras num contexto onde o planejamento urbano é ausente ou ineficaz e prejudica a mobilidade urbana como é o caso da Zona Norte de Natal, o crescimento acelerado deste espaço não foi acompanhado pelas políticas públicas resultantes do planejamento urbano ocasionando graves problemas estruturais urbanos diante de uma expressiva ocupação populacional.

Neste processo de ocupação surgem alguns elementos que foram indispensáveis na ocupação Dessa área de Natal, entre esses elementos estão algumas avenidas que deram contribuições para que o sentido norte da cidade registrasse um significativo crescimento, entre elas está a Avenida Doutor João Medeiros Filho, instrumento capital na mobilidade urbana da população da que ali reside desde sua ocupação, esta avenida possui uma função importante na reprodução do espaço, da vida e do capital na Zona Norte de Natal, porém ela não recebe a devida atenção do poder público para que de fato ela realize com facilidade sua função no contexto da Zona Norte, apresentando vários problemas que dificultam a mobilidade e a acessibilidade da população.

São as dificuldades cotidianas enfrentadas por quem mora na Zona Norte no que diz respeito à locomoção e a busca por soluções provenientes do poder público também são incluídas neste trabalho, visto que os problemas de mobilidade urbana não são elementos obrigatórios do espaço correspondente a essa região de Natal, é preciso encontrar soluções que de fato atendam a população de maneira efetiva, para isto é preciso partir da ampliação das discussões sobre mobilidade urbana nas áreas periféricas, fato que em Natal e na área de estudo em questão não se mostram de forma diferente.

\section{AVENIDA DOUTOR JOÃO MEDEIROS FILHO: UMA FOTO EM 3X4}

Atualmente, devido à expansão urbana e a intensa pressão que gira em torno da reprodução do capital é possível observar um intenso deslocamento da população nas cidades. Estes deslocamentos quando não acompanhados de uma série de medidas estruturantes que viabilizam a melhoria da vida da população no espaço urbano, impactam diretamente na qualidade de vida da sociedade. Dentre essas medidas estruturantes está o planejamento da mobilidade urbana.

Planejar a mobilidade urbana no Brasil se constitui uma ação necessária devido ao crescimento intenso de suas cidades. No entanto, a realidade é outra quando se observa que a maior parte das nossas cidades, principalmente nas suas áreas periféricas, ocupadas pela população de baixa renda. O que se observa nessas áreas são vias precárias, apresentando vários problemas que interferem na mobilidade urbana e o deficiente sistema de transporte, dividindo o espaço com a numerosa frota de veículos particulares nas principais vias de circulação. Natal há 
algum tempo vem sofrendo com essa falta de planejamento e a área de estudo em questão desde que fundada acumula problemas de infraestrutura uma vez que nenhuma reforma e/ou transformação foi ali realizada. Com o aumento do fluxo de veículos e pessoas esse problema só tem aumentado.

Algumas vias quando criadas e bem estruturadas acabam se tornando indispensáveis na articulação do fluxo de um determinado espaço, é nesse contexto que se insere a Avenida Doutor João Medeiros Filho, visto que uma considerável parcela do tráfego da Zona Norte de Natal ali circula. Todavia, com a expansão dessa área, esta via não recebeu, ao longo de décadas, os investimentos necessários em infraestrutura para que fosse possível o desempenho do seu papel enquanto via estrutural arterial de circulação, como assim é classificada pelo poder público municipal. A inserção do sentido norte no contexto Urbano da cidade de Natal transformou a estrada da Redinha em Avenida Doutor João Medeiros Filho, o termo "Estrada" fazia referência ao contexto rural em que a atual Zona Norte estava inserida, como aponta SOUZA quando nos diz que

O espaço urbano da atual zona norte de Natal em meados do século XX pertencia às cidades de São Gonçalo do Amarante e Extremoz, hoje integrantes da região metropolitana de Natal, eram terrenos de sítios e algumas fazendas, não apresentando nenhum aglomerado urbano até a década de 70 (SOUZA, 2000, p. 18).

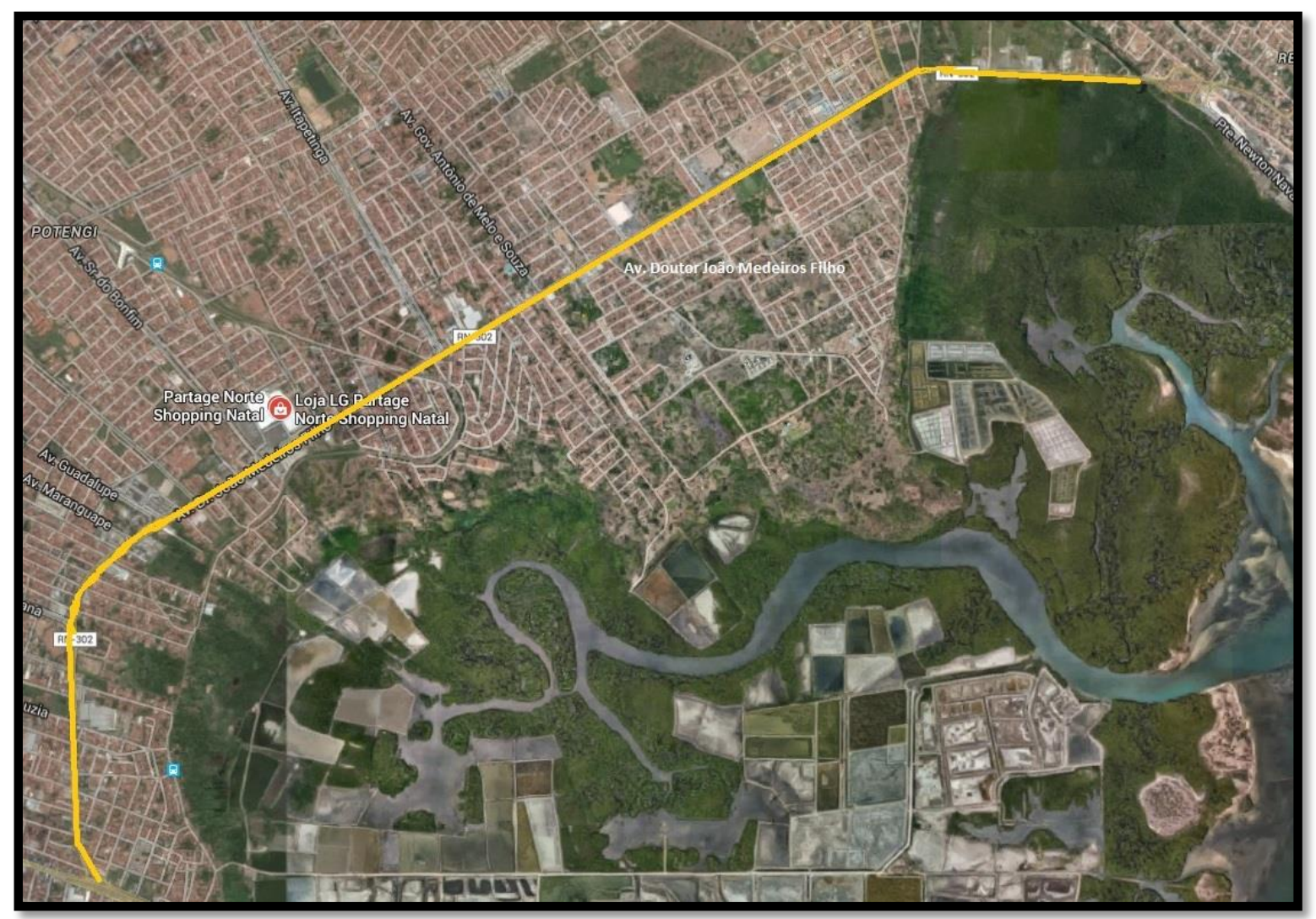

Figura 01 - Imagem de satélite da Avenida Doutor João Medeiros Filho Fonte: Imagem adaptada pelo autor, 2016.

O crescimento acelerado da Zona Norte de Natal a partir de 1970 proporcionou fortes pressões no orçamento público dificultando o fornecimento de determinados serviços de consumo coletivo, essas questões acabaram por penalizar sua população na questão do oferecimento 
precário de infraestrutura adequada, inclusive viária o que acabou por aumentar o tempo gasto nos deslocamentos diários feitos pela população, dificultando cada vez mais a acessibilidade a outras áreas da cidade, ampliando as suas desigualdades socioespaciais.

Assim, essa expansão urbana pressionou o poder público a partir de 1975 a executar reformas nesta área, dentre elas destacamos a pavimentação da estrada da Redinha. Em uma dessas reformas em 1989 a estrada da Redinha passou a se chamar Avenida Doutor João Medeiros Filho em homenagem a um desembargador paraibano importante na história do Rio Grande do Norte. Todavia, a alteração da nomenclatura não contribuiu para a aplicação de melhorias futuras na Avenida (LIMA, 2001).

No que diz respeito ao espaço urbano, a acessibilidade e a mobilidade oferecidas pelas vias de circulação são fatores fundamentais na estruturação do espaço, no entanto antes e durante o processo de ocupação da Zona Norte de Natal a Avenida Dr. João Medeiros filho desempenhou muito mais do que seu papel de fornecer mobilidade e acessibilidade, esta desempenhou um papel atrativo que mais tarde implicaria na expansão urbana no sentido Norte de Natal, como destaca Silva $(2003$, p. 106)

A partir de 1952 a "estrada da Redinha" (atual avenida Dr. João Medeiros Filho) começou a ser aberta ligando Igapó e Redinha, o que possibilitou a expansão urbana de Natal para o Norte atraindo investidores imobiliários e interessados em adquirir terras a um preço muito baixo e revendê-las em forma de lotes. Todavia, antes da década de 1970 eram apenas estradas como afirma (ARAÚJO, 2004, p. 80)

[...] Com a instalação do DIN no entorno da zona norte, a conhecida estrada "Natal/Ceará-Mirim" cedeu lugar a atual Avenida Tomaz Landim, figurando como um corredor de acesso às atividades industriais, assim como a estrada "Natal/Redinha" passou a abrigar, em eixos perpendiculares, ao longo de sua extensão, os numerosos conjuntos habitacionais, cedendo lugar para a atual Avenida João Medeiros Filho.

A capacidade de articular grandes volumes de tráfego pode ser afetada na medida em que a população cresce e as políticas públicas relativas à mobilidade urbana não acompanham este crescimento. No caso da João Medeiros Filho, o crescimento socioeconômico e populacional determinou o aumento nos padrões de uso do seu sistema viário que, sem o devido planejamento acaba por apresentar ao longo do tempo aspectos negativos inerentes a sua mobilidade urbana.

Assim, os aspectos relativos à imobilidade surgem no espaço como resultado de políticas públicas não eficientes. No caso da Avenida Doutor João Medeiros Filho, um fator agravante para a sua mobilidade é que os bairros mais populosos da Zona Norte utilizam a Avenida como principal corredor de acessibilidade e mobilidade causando todos os dias enormes engarrafamentos, principalmente nos horários de pico, problema que por sinal é bem antigo e sentido por quem ocupa a Zona Norte. Sobre essa questão, observemos a fala abaixo.

O principal problema dessa avenida é esse engarrafamento que parece lei todos os dias, moro aqui há décadas e parece que este problema nunca tem fim, só piora a cada dia e dobra o cansaço de quem mora na Zona norte e precisa da João Medeiros para trabalhar. (Morador da Zona Norte, informação verbal, 2016). 
À medida que as cidades vão se expandindo, planejar a mobilidade e a acessibilidade se torna indispensável uma vez que o deslocamento de grande contingente de pessoas na cidade capitalista implica em uma grande pressão sobre o espaço urbano, assim, na ausência de um planejamento no que diz respeito à acessibilidade e mobilidade, emergem sérios danos na qualidade e no tempo de deslocamento da população, ocasionando problemas de ordem econômica e social como, por exemplo, a dificuldade para conseguir emprego pelo fato da dificuldade de transporte, o aumento do estresse devido ao tempo de deslocamento e a pouca acessibilidade aos outros espaços da cidade.

Nesse sentido, as pressões no sistema viário são potencializadas no Brasil devido ao incentivo a posse do transporte individual, fato que em Natal não é diferente. Segundo Gomide, Leite e Rabelo (2006, p. 28) o uso intensivo do automóvel é responsável pela geração de várias externalidades negativas tais como: os acidentes de trânsito, os congestionamentos de tráfego entre outros.

Esta afirmação possibilita a observarmos que os problemas que são pertinentes à mobilidade urbana no Brasil possuem uma grande contribuição do uso do carro particular de maneira intensiva elevando as pressões no seu sistema viário, fato comprovado na capital potiguar. Em Natal verifica-se que as políticas e as gestões públicas tem privilegiado o uso do automóvel, fazendo com que ocorra um processo de deterioração das condições de operação da mobilidade urbana (COSTA, 2014. p.13).

\section{AVENIDA JOÃO MEDEIROS FILHO E MOBILIDADE URBANA}

No tocante a Avenida Dr. João Medeiros Filho as pressões em seu sistema de escoamento de fluxo são visíveis principalmente nos horários de pico como já mencionado, no início da manhã e no início da noite, a avenida não consegue articular de maneira satisfatória o fluxo que vem recebendo se tornando um expressivo símbolo de lentidão e ausência de mobilidade para que a utiliza. Nesse contexto, a expansão demográfica da Zona Norte de Natal transformou a João Medeiros em um instrumento vital para a reprodução da vida nesta área da cidade, uma vez que há algumas décadas atrás, antes da acelerada ocupação dessa área da cidade, esta avenida possuía uma função menos complexa do que a atual. Segundo Chaves (2012, p.71), a abertura da Estrada da redinha foi iniciada em 1952 pela Prefeitura Municipal de Natal (PMN), todavia, somente "com a bravura de Humberto Teixeira, veranista da praia da Redinha que a obra foi finalizada, ligando os povoados de igapó e Redinha".

Devemos considerar também que na configuração urbana espacial da Zona Norte de Natal, a Avenida Doutor João Medeiros Filho se conecta com outras avenidas e é responsável por articular o fluxo que é proveniente dos grandes bairros de sua hinterlândia. Avenidas como a Moema Tinoco, Itapetinga, Governador Antônio Melo de Souza, Maranguape, Paulistana e Senhor do Bonfim, constituem-se corredores que contribuem significativamente para o intenso fluxo registrado na João Medeiros e se conectam com a mesma. 


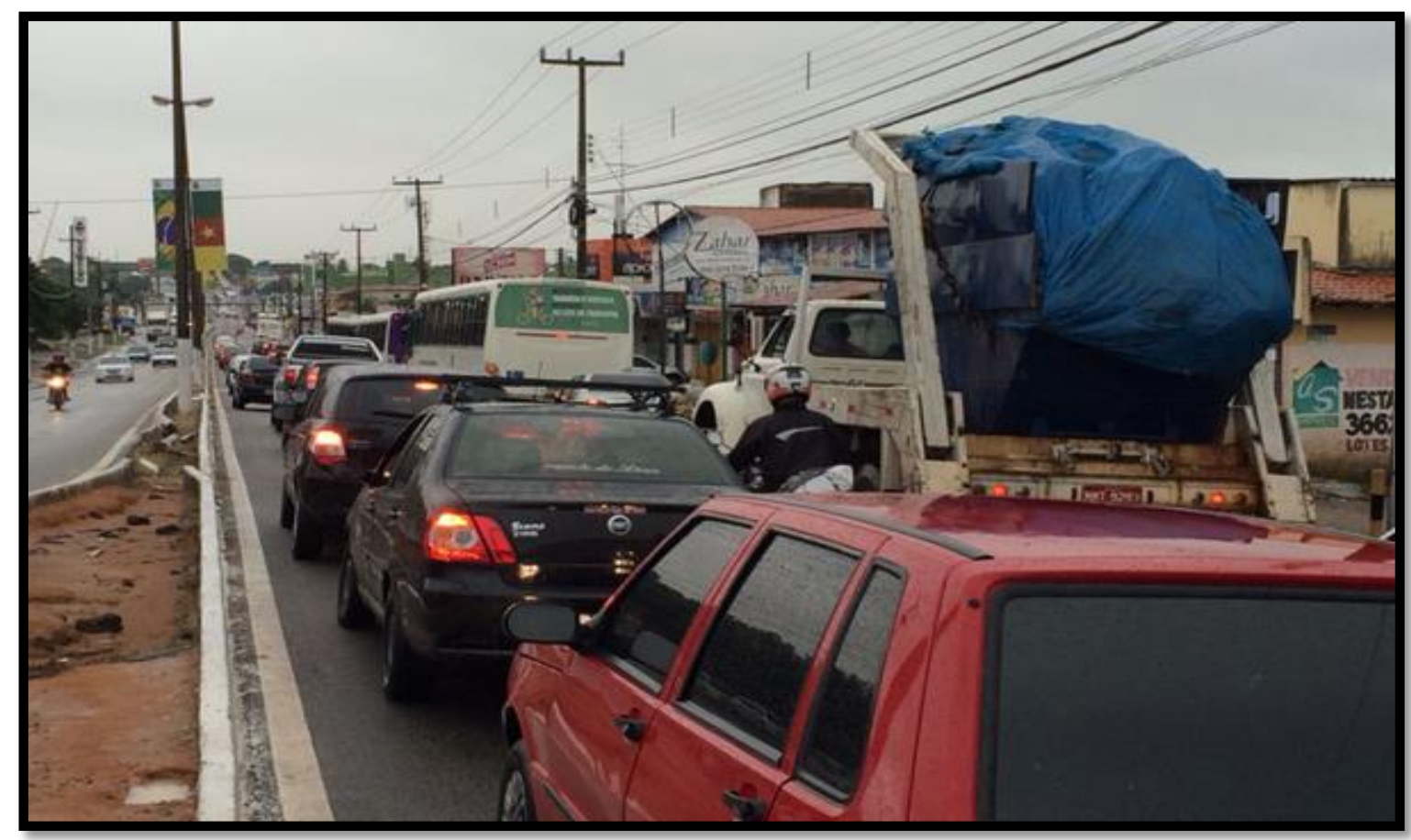

Figura 02 - Avenida Doutor João Medeiros Filho na Altura da Avenida Maranguape Fonte: ABREU, 2016.

Outro fato a ser considerado é que as avenidas que se conectam com a Avenida Doutor João Medeiros Filho cortam um ou mais bairros populosos da Zona Norte ${ }^{1}$ cuja população para desenvolver atividades importantes inerentes ao seu cotidiano, geralmente utilizam a João Medeiros parar ter acesso aos serviços urbanos, seja ele na própria Zona Norte da cidade ou em outra área da cidade.

É importante ressaltar que alguns dos problemas relativos à mobilidade urbana que surgem na Avenida Doutor João Medeiros são ocasionada pela exacerbada pressão exercida sobre as vias que estão ligadas a João Medeiros, um exemplo claro é a lentidão no sentido em direção a Ponte Newton Navarro nos horários de pico e que recebe um intenso fluxo da Avenida Moema Tinoco. Outro exemplo é o longo congestionamento no início do período da manhã no sentido Ponte Presidente Costa e Silva (Ponte de Igapó) que recebe uma notável contribuição da incapacidade da Avenida Tomaz Landim em articular todo o fluxo que ela recebe como é possível observar na figura 09.

A mobilidade urbana em áreas periféricas ocupadas pela população de baixa renda consiste em uma das questões mais inerentes quando o assunto é o deslocamento intraurbano. A Avenida Doutor João Medeiros Filho sofre com os efeitos perversos relativos ao uso intenso do automóvel, congestionamentos, acidentes de trânsito e a deterioração da estrutura viária devido ao seu intenso tráfego. Estes são alguns dos fatores relativos à centralidade na política do automóvel que agregam negatividades a avenida em detrimento do transporte público de qualidade.

\footnotetext{
${ }^{1}$ Pajuçara, Potengi, Lagoa Azul, Salinas e Nossa Senhora da Apresentação.
} 


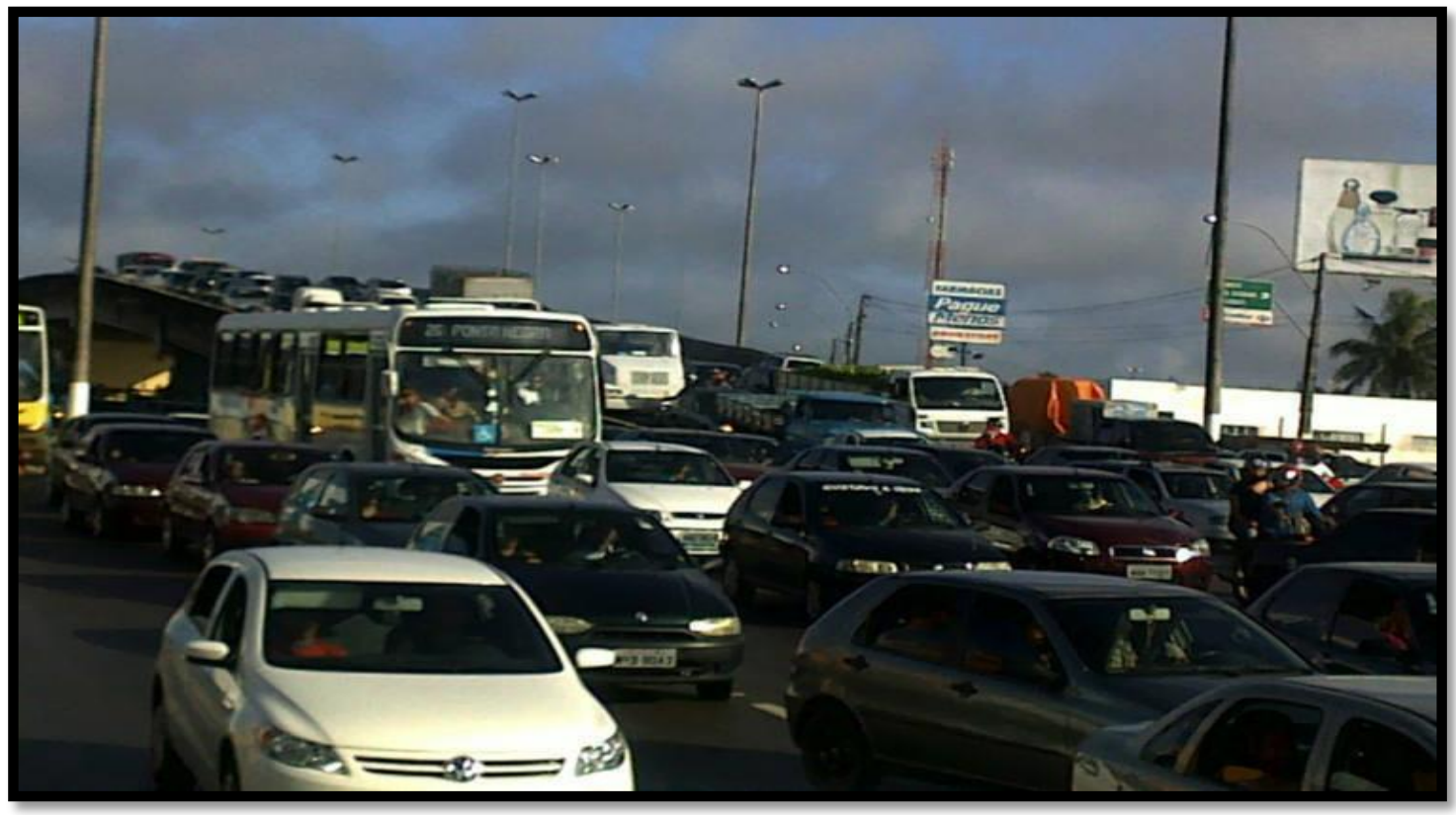

Figura 03 - Congestionamento matinal na Avenida Tomaz Landim. Fonte: CLARIM, 2014.

Pelo fato de ser uma avenida que apresenta uma grande quantidade de atividades ligadas ao comércio e aos serviços, a João Medeiros Filho em alguns pontos se torna um espaço em disputa por aqueles que querem transitar ao longo da via e por aqueles que querem estacionar seus veículos. Em alguns casos o fato de estacionar um ou mais veículos interfere em outras questões como, por exemplo, a velocidade média da Avenida, sobretudo nos horários de pico e até mesmo a determinação onde o transporte coletivo vai parar como fica compreendido na fala abaixo.

[...] Os carros que estacionam em local irregular aqui nessa Avenida é um problema, pela manhã e no início da noite a lentidão toma conta e quando você vai ver por vezes é um carro estacionado ocupando uma faixa, atrapalha até os ônibus que param fora da parada ou passam pela outra faixa e acabam não parando, aumentando ainda mais o tempo de espera, é assim que é a realidade daqui. (Motorista de ônibus, informação verbal, 2016).

A partir desta informação concedida é possível compreender que a avenida necessita do poder público não só para questões de infraestrutura, como também para questões da manutenção do respeito às leis que respeitem a mobilidade urbana. No tocante aos deslocamentos intraurbano por meio do transporte público, essa avenida possui um papel indispensável na mobilidade e acessibilidade das massas.

Segundo Souza Filho (2015, p. 09), das trinta e sete linhas de ônibus urbanos que circulam pela Zona Norte de Natal, 25 trafegam pela Avenida Doutor João Medeiros, somados aos interurbanos e transportes alternativos. Este fato evidencia a importância que esta avenida desempenha na mobilidade e acessibilidade de uma significativa parcela populacional da Zona Norte bem como da cidade como um todo, uma vez que muita gente trabalha nessa área da cidade mais são oriundas de outras áreas da cidade.

Embora o número de linhas que trafegam pela Avenida Doutor João Medeiros Filho seja esse, enquanto avenida principal dessa área, não é suficiente para as dimensões demográficas da 
zona norte de Natal na atualidade uma vez que muito pouco foi feito, em termos de infraestrutura que acompanhasse o crescimento da Zona Norte. É muito comum, principalmente nos horários de pico, as paradas estarem lotadas, ônibus superlotados além da demora destes na condução da sociedade aos seus itinerários habituais.

Apesar de todo o ritmo crescente de expansão urbana da Zona Norte, constatamos que tanto a João Medeiros bem como as avenidas que dão mobilidade a população continua sendo as mesmas. Sem projetos de criação de vias alternativas, provoca sérios problemas de mobilidade urbana, assim, estes problemas se tornam mais graves devido a outros fatores ligados a falta de infraestrutura urbana ${ }^{2}$

Outro aspecto levantado pela sociedade enquanto problema nessa área da cidade diz respeito ao distanciamento do poder público a população da Zona Norte. Todos os dias nas atividades que remetem ao cotidiano do morador, trabalhar, estudar são algumas das atividades que estão interligadas aos deslocamentos da população nas periferias urbanas, as dificuldades na acessibilidade e na mobilidade pode conduzir o indivíduo a pensar que nem na cidade em que mora, ele está inserido ou até mesmo de não existência aos olhos do poder público, como é percebido na afirmação abaixo

A população da zona norte é esquecida, estes engarrafamentos e essas dificuldades com relação aos coletivos não são de hoje, são de muito tempo, faz 28 anos que moro na zona norte e me parece que nós não somos Natal ou nem existimos, só em época de eleição, todos os dias temos que encarar os velhos problemas pra sair da zona norte para as nossas ocupações [...] (LIMA, p. 129, 2011).

Diante desta afirmação, constatamos a indignação da sociedade com os problemas relacionados à mobilidade urbana e a questão da acessibilidade são o retrato da omissão do poder público com relação às resoluções de problemas estruturais em áreas de menor poder aquisitivo, o acúmulo de problemas e o quanto eles perduram no espaço provoca na população um sentimento de indignação e de descrença nas melhorias quando o assunto é mobilidade urbana, visto que as necessidades básicas ligadas à sobrevivência e a reprodução da vida nas cidades se interligam a questão da mobilidade urbana.

Outro problema sentido pelos moradores que utilizam a Avenida Doutor João Medeiros Filho são os congestionamentos em vários pontos, alguns incomodam a população há décadas, como é o caso do que surge no início da manhã no sentido Redinha-lgapó na altura do conjunto Panatis. Congestionamentos antigos sem resolução e o acúmulo de problemas de infraestrutura urbana em áreas periféricas conduz a população a pouco crer em melhorias. A segregação socioespacial e a segregação do modelo econômico condenam à população duas vezes à pobreza (SANTOS, 2000, p.115). Esta dupla condenação por sua vez provoca certo conformismo por parte da população com os problemas que surgem na periferia, inclusive os que se relacionam com a mobilidade urbana. A fala abaixo corrobora o que atestamos em nosso trabalho de campo.

Eu sinceramente acredito que os projetos de mobilidade para João Medeiros Filho vai mudar pouca coisa na vida do trabalhador que precisa desse corredor pra se deslocar, as coisas do governo demoram demais, ainda mais quando é pra zona

\footnotetext{
${ }^{2}$ Precária iluminação pública, deteriorada sinalização vertical e horizontal e buracos no assoalho viário.
} 
norte, só fico indignado, pois aqui é maior zona entre as quatro da cidade e precisa mais do apoio dos políticos e acontece justamente o contrário, por enquanto acredito não haver melhorias. Estamos muitos descrentes dos políticos nessa questão aqui na João Medeiros Filho.

Nesse contexto, no que diz respeito à Zona Norte de Natal o acesso amplamente democrático do espaço urbano se torna um desafio justamente pela ineficácia de políticas públicas voltadas para a mobilidade urbana, que contrariamente a política nacional segrega mais ainda a cidade. A ineficácia de políticas públicas relativas à mobilidade urbana sustentável é sentida pela ausência de quatro práticas essenciais: o planejamento integrado de transporte e uso do solo urbano, a atualização e gestão do transporte coletivo urbano a promoção da circulação não motorizada e o uso racional do automóvel (Ministério das Cidades, 2004, p. 22).

$O$ desgaste no qual está fadado o indivíduo que ocupa as áreas de menor poder aquisitivo no contexto urbano capitalista se torna uma realidade quando índices positivos de acessibilidade e mobilidade em áreas periféricas onde se concentra a população de baixo poder aquisitivo se tornam cada vez mais um desafio para o poder público devido ao ritmo de crescimento demográfico e ocupacional destas áreas.

No caso da Avenida João Medeiros Filho, a má qualidade do transporte público que é vital para o acesso de uma parcela dos moradores da Zona Norte a outras áreas da cidade e mais precisamente para sua sobrevivência, juntamente com a má qualidade na mobilidade urbana, ceifa o tempo destinado a outras atividades e os condenam a sofrer diariamente os efeitos das insuficientes medidas que visam à ampliação da acessibilidade e da mobilidade na Zona Norte de Natal.

As políticas públicas foram insuficientes perante o acelerado ritmo de crescimento da Zona Norte de Natal, a intensa urbanização da cidade na segunda metade do século XX e consequentemente a acentuada ocupação periférica, acabou por gerar problemas que agregam negatividades a qualidade de vida da população da Zona Norte. Além dos semáforos, a falta de manutenção na estrutura viária da avenida contribui para o surgimento de determinados problemas, a ausência do poder público refletida na precária infraestrutura das ruas e avenidas nas áreas periféricas dificulta a vida das pessoas que dependem da João Medeiros diariamente.

Sem dúvida, o crescimento da Zona Norte de Natal trouxe junto consigo grandes pressões as principais ruas e avenidas devido à intensa circulação de pessoas e veículos ao longo do dia, diante disso, o poder público é conduzido a tomar medidas de organização do tráfego que nem sempre funcionam a contento, como é o caso da instalação de semáforos. Todavia, estes em determinados horários do dia na Avenida João Medeiros Filho se tornam símbolos da lentidão, logo, de pouca mobilidade, visto que há nove deles ao longo de toda a Avenida (Souza Filho, 2015 p.06).

Assim, constatamos que os problemas de infraestrutura viária que emergem na Avenida Doutor João Medeiros Filho no que se refere à mobilidade urbana contém um histórico de frequência bem significativo, por ser uma avenida importante no contexto da Zona Norte, estes problemas ganham proporções maiores pelo intenso uso atual de seu espaço viário e à medida que esta região cresce e novos serviços e habitações vão surgindo. 
Todavia, no início do mês de janeiro de 2016 problemas com a pequena estrutura que passa acima do Rio Doce nas proximidades da Ponte Newton Navarro, ilustradas na figura 10 resultou na interdição de uma das faixas, mudanças de itinerários de linhas de ónibus e uma considerável lentidão no sentido em direção a Ponte Newton Navarro, impactando na mobilidade da João Medeiros Filho, prejudicando, moradores, comerciantes e o setor turístico. Esse problema até o termino de nossa pesquisa ainda não havia sido solucionado.

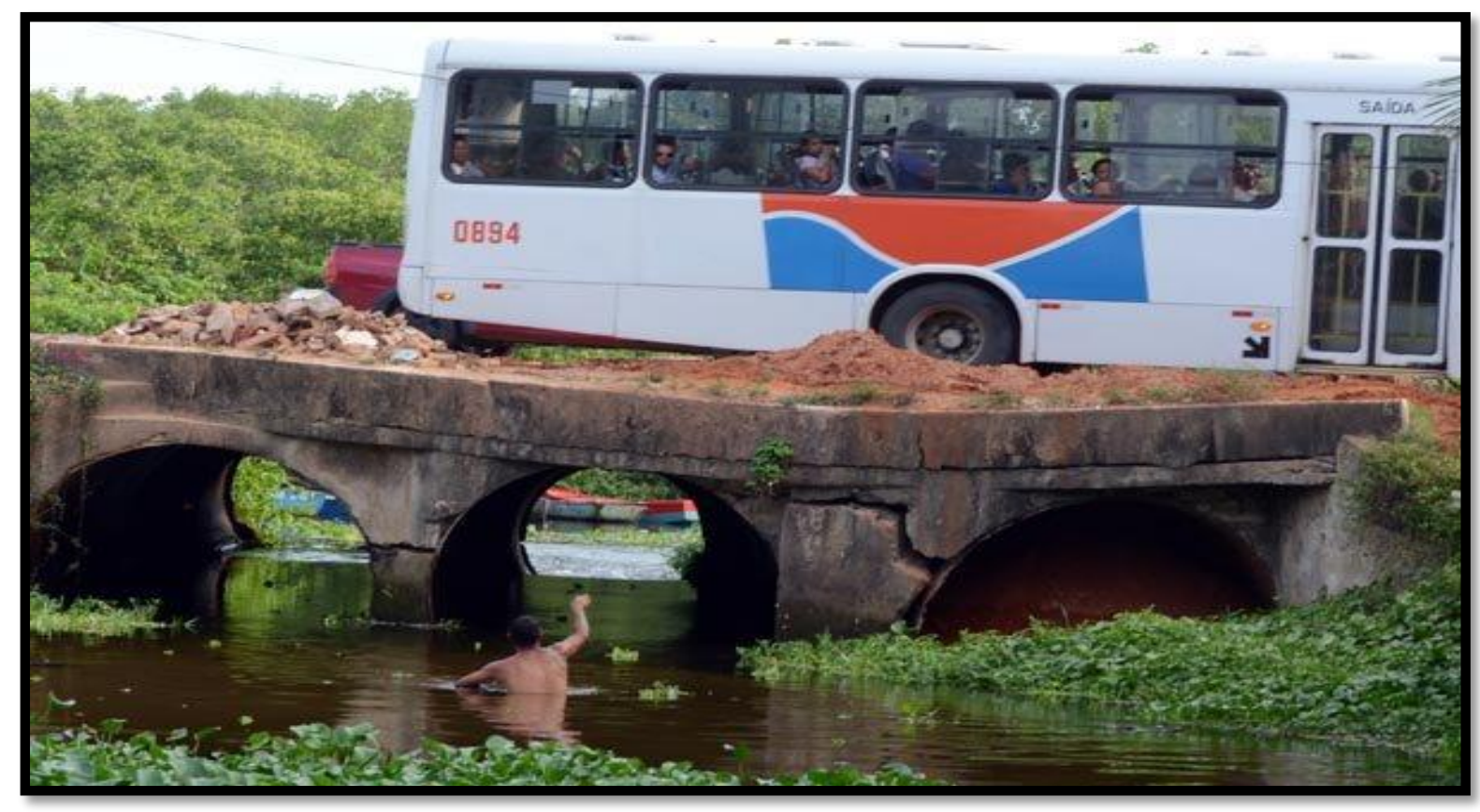

Figura 4 - Ponte sobre o Rio Doce na Avenida Doutor João Medeiros Filho.

Fonte: ABREU, 2016.

Este como em outros casos por hora foi tomada uma medida paliativa que acaba, em longo prazo, ampliando os transtornos a população de menor poder aquisitivo no sentido norte da cidade, que utiliza a mobilidade urbana como ferramenta para sobrevivência no espaço urbano, sofre com medidas que não visam resolver os problemas de sua principal avenida e sim apenas diminuí-los.

A partir da observância de determinados transtornos e precariedades supostamente contornados com medidas paliativas na João Medeiros Filho, é possível apontar a ausência do Estado enquanto agente produtor do espaço urbano uma vez que, o Estado no Brasil é responsável pela implantação da infraestrutura urbana nas cidades. (QUEIROZ, 2010, p. 03). Neste mesmo sentido a Doutor João Medeiros Filho desempenha um papel indispensável para uma grande parcela da zona norte de Natal, visto que a condição de ser inserido ou não no contexto urbano de Natal para uma considerável parcela da população, passou e ainda passa pela Avenida em questão.

É importante ressaltar que o projeto pró-transporte possui também em seus objetivos principais a melhoria do acesso aos transportes coletivos, estes em meio à população de baixa renda são capitais para sobrevivência. Acreditamos que é neste sentido que transporte, mobilidade e acessibilidade são colunas de sustentáculo do projeto que possui como diretriz ampliar de maneira significativa a mobilidade urbana da população da Zona Norte, visto que este projeto em si procura atender de alguma maneira toda essa região da cidade. O projeto pró-transporte baseado na política nacional de mobilidade tem por finalidade propiciar o aumento da mobilidade urbana e da acessibilidade, no tocante a zona norte o projeto se divide em dois eixos: O eixo fronteiras que pretende ampliar a capacidade de fluxo na Avenida das fronteiras do bairro do Igapó até a Avenida 
Moema Tinoco, desafogando o intenso fluxo ocorrido na João Medeiros Filho. O outro eixo é o eixo redinha que na verdade é a continuação do primeiro eixo, nesta etapa a duplicação e ampliação de avenidas também é uma realidade, porém neste eixo está inserido também o projeto do viaduto da redinha ilustrado na figura 11 que obterá a função de distribuir principalmente o fluxo vindo da Newton Navarro ou o fluxo que vai em direção a ela.

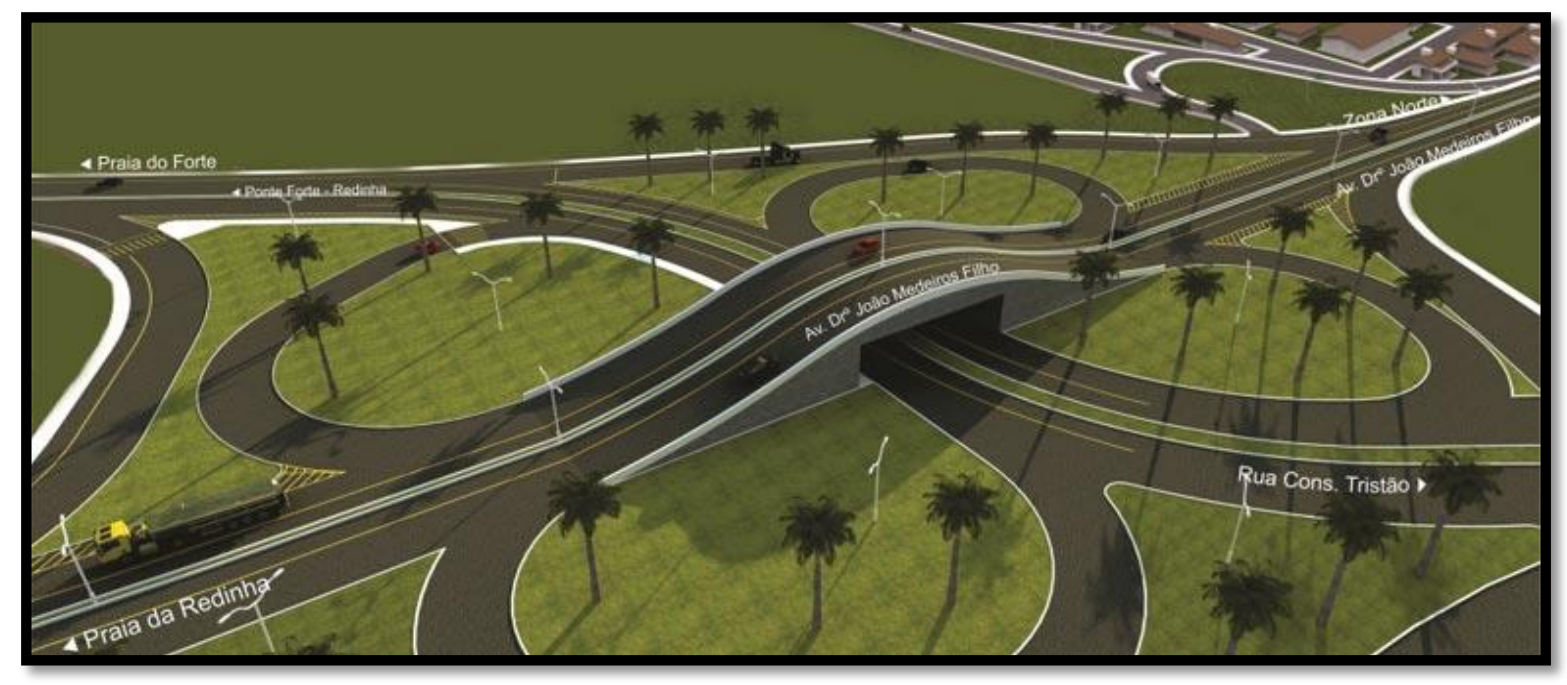

Figura 5 - Projeto do Viaduto da Redinha- Pró-Transporte. Fonte: SEPLAN/RN, 2014.

Ações como esta do projeto pró-transporte concedem esperança de melhorias a uma parcela da população que sofre há décadas com problemas de mobilidade e acessibilidade, embora as obras avancem com lentidão, ao final da execução delas os ganhos para a população da zona norte como um todo será significante, todos os problemas não serão resolvidos com a conclusão do projeto, porém é um grande passo para a melhoria da mobilidade na Zona Norte de Natal e causa grandes expectativas para quem trafega pela Avenida. A fala abaixo expressa esse sentimento desejo de melhoria nesta avenida quando nos mostra que

Eu espero que alguns problemas antigos sejam resolvidos com essas obras, à população da zona norte merece um pouco de melhoria em alguns setores, inclusive na questão da mobilidade urbana, parece um sonho que nós fomos comtemplados com essas obras. (Morador da Zona norte, informação verbal, 2016).

No que diz respeito à Avenida Doutor João Medeiros Filho o projeto pró-transporte criará basicamente um grande complexo viário paralelo a ela, diminuindo consideravelmente a pressão sobre seu sistema viário, porém a intensidade de circulação na João Medeiros não cessará pelo fato da quantidade de comércios e serviços existentes na avenida e também pelo fato de o acesso a alguns conjuntos habitacional só ser possível por meio da João Medeiros Filho.

$\mathrm{Na}$ atualidade as obras relativas a este projeto se encontram paralisadas aumentando a estimativa de tempo para sua conclusão. Em alguns pontos, como é o caso da Avenida das fronteiras que será uma via alternativa paralela a João Medeiros Filho, as obras se encontram paradas e incompletas e a única obra de concreto pronta é o viaduto na altura do Conjunto Santa Catarina ilustrado na Figura 12. 


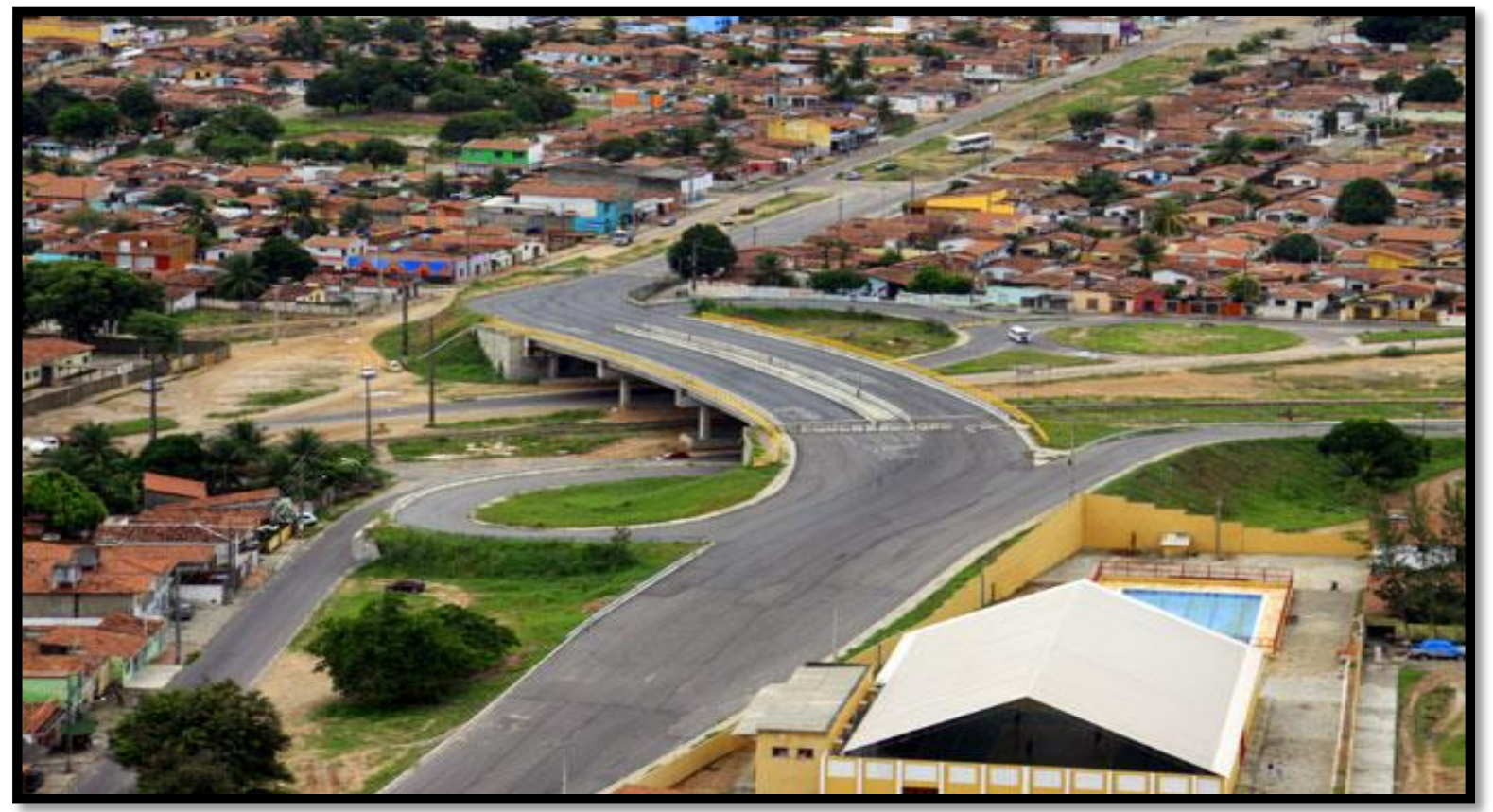

Figura 6 - Viaduto do Conjunto Habitacional Santa Catarina.

Fonte: CLARIM, 2014.

As melhorias com a finalização do projeto pró-transporte na Zona Norte de Natal possibilitará um novo panorama no que diz respeito à mobilidade urbana. No tocante a João Medeiros Filho a diminuição do fluxo será resultado da criação de outros eixos viários previstos no projeto $^{3}$. Neste caso estima-se que a Avenida Doutor João Medeiros Filho que foi uma mera estrada de ligação de povoados em um contexto rural, não perderá sua importância no contexto urbano, a reprodução da vida e do urbano na zona norte de Natal está imortalizada no vai e vem desta avenida e se fez um instrumento importante no desenvolvimento do sentido norte da cidade do Natal.

É importante observar que à Avenida Doutor João Medeiros Filho contribuiu de maneira significativa para a expansão urbana da Zona Norte da cidade. Sua funcionalidade é evidente na expansão da Zona Norte no sentido Igapó-Redinha. Atualmente ela desempenha papeis diversos nos circuitos superior e inferior da economia, no turismo e, sobretudo na questão da acessibilidade de grande parte da numerosa população da região e áreas adjacentes, ou seja, trata-se de um importante corredor viário urbano da cidade.

\section{CONSIDERAÇÕES FINAIS}

Sendo uma questão indispensável para o desenvolvimento do espaço urbano capitalista a mobilidade urbana se torna um instigante elemento de discussão acerca da vida nas cidades, discutir mobilidade urbana e todos os desafios que a cerca, adiciona cada vez mais elementos na pauta de planejamento urbano no Brasil.

Natal seguindo o modelo segregacionista urbano capitalista gerou espaços de desigualdades que acabam por condenar uma parcela da população a viver entre negatividades resultantes do insuficiente ou inexistente planejamento urbano, neste sentido a zona norte de

3 Eixo fronteiras e eixo Moema Tinoco. 
Natal apresenta entre tantas negatividades a questão das precárias condições de mobilidade urbana, que para a população de menor poder aquisitivo se trata de um instrumento indispensável para a reprodução da vida no contexto urbano.

O diagnóstico da situação do morador da Zona Norte de Natal com relação à mobilidade urbana apresenta um acúmulo de características negativas que atinge até mesmo a sua autoestima enquanto cidadão, a discussão da mobilidade urbana em áreas de baixo poder aquisitivo amplia a discussão de aspectos ligados à desigualdade social característica nas sociedades capitalistas, demonstrando aspectos que por vezes não são percebidos pelo poder público e o abandono em que se encontram no sentido de políticas públicas as zonas periféricas ocupadas pela população de baixo poder aquisitivo no Brasil.

A Ponte Presidente Costa e Silva e a Ponte Newton Navarro são receptáculos do tráfego da Avenida Doutor João Medeiros filho, os bairros já existentes no seu entorno e os novos empreendimentos imobiliários que surgem, direciona a população a utilizar a Avenida Doutor João Medeiros Filho como principal via de circulação, ou seja, a acessibilidade e a mobilidade de uma considerável parcela da população da zona norte depende da Avenida em questão, o que acaba gerando intensos congestionamentos nos períodos matinais e inicial noturno.

A situação da população que necessita da Avenida Doutor João Medeiros Filho todos os dias para sobreviver no espaço urbano, comprova a afirmativa que viver na periferia é uma dura e dupla condenação à pobreza, por meio da pesquisa foi possível perceber a importância que a avenida em questão desempenha na vida de uma considerável parcela da população dessa área de Natal e também a conformidade da população com os problemas inerentes a ela, como se estes fossem parte do espaço e sua presença fosse natural e imutável, essa realidade compõe a dura vida do indivíduo que reside na maior zona administrativa da cidade do Natal em termos populacionais, apesar das dimensões populacionais a política de mobilidade se mostra insuficiente para atender as pessoas que ali vivem.

A profunda analise do espaço geográfico resulta na demonstração das situações e contradições presentes e um determinado contexto, no caso da João Medeiros Filho a grande contradição é a importância que ele desempenha dentro da zona norte de Natal e o abandono com relação a políticas públicas que sofre este importante corredor viário, este abandono resulta em inúmeras implicações negativas para a população e geram problemas de ordem social e econômica.

A insuficiente política de mobilidade geram também problemas que por vezes passam despercebidos das discussões, um exemplo disso são os congestionamentos que em grandes proporções se tornam até uma questão de saúde, a população que sofre com eles ficam mais tempo expostas ao sol ou a chuva, mais tempo em contato com a poluição e com a sujeira dos precários transportes coletivos e em alguns casos mais tempo em contato com pessoas doentes nos lotados ônibus que circulam pela periferia.

O tempo, objeto precioso nas sociedades capitalistas é extremamente desperdiçado pela população da zona norte que utiliza a Avenida Doutor João Medeiros Filho, quando a questão é mobilidade urbana o precário sistema de transporte, os longos congestionamentos nos horários de pico nas adjacências das duas pontes, a deficiente infraestrutura viária e a insuficiente política de mobilidade, dão contornos negativos as vias periféricas, neste mesmo sentido a imobilidade urbana é uma tendência crescente na Avenida em questão. 
Mediante aos problemas relativos à mobilidade e acessibilidade identificados por meio da análise espacial, é evidente que os serviços e equipamentos urbanos precisam ser melhorados para que de fato a população da zona norte possa ser mais inserida no contexto urbano da cidade do Natal, visto que as dificuldades de acessibilidade e mobilidade limitam as oportunidades de quem reside na zona norte, confrontando com a política nacional de mobilidade urbana que entende que esta deve ser um instrumento de inclusão social.

O desejo de uma melhor inclusão no espaço urbano é sentido no clamor dos indivíduos que residem na Zona Norte por melhorias na infraestrutura urbana, principalmente na resolução de velhos problemas de ordem viária que perturbam a qualidade de vida da população, discutir mobilidade urbana em zonas periféricas é discutir o difícil cotidiano correspondente à luta diária de quem vive nas periferias. Os problemas observados na Avenida Doutor João Medeiros Filho são amostras dos problemas de mobilidade e acessibilidade enfrentados por outras vias na Zona Norte de Natal, as entrevistas, a observação e reflexão dos aspectos que envolvem o espaço em questão, possibilitam a construção da ideia que a melhoria na infraestrutura urbana nas principais avenidas da zona norte consiste em uma situação de urgência.

A expansão imobiliária da Zona Norte impulsiona mais ainda essa necessidade de implantação de melhorias no que diz respeito à acessibilidade e mobilidade, a valorização imobiliária, a construção e ocupação de condomínios e a ausência de políticas públicas se tratam da combinação perfeita para o estrangulamento viário da Avenida Doutor João Medeiros Filho, por isso o planejamento urbano é algo indispensável para o controle e ordenamento do crescimento das cidades para que de fato a gestão pública possa minimizar os efeitos das desigualdades urbano espaciais. O estudo realizado evidencia a produção diferenciada do espaço no processo de urbanização de Natal, esta produção seguiu interesses dos agentes produtores do espaço urbano e no caso da zona norte, estes interesses impactaram diretamente de maneira negativa em alguns setores essenciais, contribuindo para as características presentes no espaço atual.

Outro importante apontamento evidenciado pela pesquisa é que o Estado enquanto poder público, responsável pela instalação de equipamentos urbanos coletivos, para que se inclua socialmente a população periferizada, contorna os problemas relativos a mobilidade com medidas de caráter paliativo, adiando e ampliando em alguns casos os problemas relativos a mobilidade e acessibilidade. Esse caráter paliativo característico das ações do Estado compõe o quadro cotidiano da mobilidade urbana e acessibilidade para quem reside na região, a lentidão, a insuficiência e até mesmo a inexistência de políticas que priorizem melhorias para a população, são sentidas nos discursos dos moradores quando o tema é melhoria nas principais vias da Zona Norte.

A pesquisa aponta projetos que mediante o crescimento da zona norte já deveria ser realidade em termos de funcionamento, assim Avenidas como Tomaz Landim, Moema Tinoco e João Medeiros filho não apresentariam uma realidade tão negativa quando o tema é mobilidade e acessibilidade, a construção de corredores alternativos viários e outras ações que distribuam o fluxo são medidas possíveis e urgentes para a questão da mobilidade urbana na Zona Norte.

Apesar de ser um projeto interessante para as melhorias em termos de infraestrutura viária na zona norte, o Pró- transporte não resolve todos os problemas relativos à mobilidade e acessibilidade da Zona Norte, a manutenção da política do carro particular anulará as melhorias conquistadas por meio da execução do Pró- transporte, o oferecimento do transporte público de qualidade e diversificado associado com a produção de um sistema viário que priorize o transporte 
de público de qualidade, deverá ser um grande passo para a inclusão social daqueles que habitam no abandono da segregação urbana e consequentemente da melhoria da mobilidade urbana não só da Zona Norte mas da cidade como um todo.

\section{REFERÊNCIAS}

1. ARAÚJO, Josélia Carvalho de. Outra leitura "do outro lado": O espaço da zona norte em questão. UFRN, Natal, 2004.

2. COSTA, Luzimar Pereira da. Análise da mobilidade urbana em Natal/RN a partir do uso de indicadores de sustentabilidade. Natal, 2014.

3. CHAVES, Monick Ezequiel. Zona norte de Natal: Uma análise sócio espacial da influência dos serviços Avenida Doutor João Medeiros Filho/ Monick Ezequiel Chaves- 2012.

4. GOMIDE, Alexandre de Ávila. LEITE, Sabina Kauark. REBELO, Jorge. Transporte público e pobreza urbana: um índice-síntese de serviço adequado.Brasília: IPEA, 2006 (Texto para discussão, n. 1209). Disponívelem:<http://www.ipea.gov.br/sites/000/2/publicacoes/tds/ td_1209.pdf>. Acesso em: 10 jan. 2015.

5. MINISTÉRIO DAS CIDADES. Política nacional de mobilidade urbana sustentável. Caderno cidades mobilidade urbana. Brasília: 2004.

6. LIMA, Pedro de. Natal século XX: Do urbanismo ao planejamento urbano. Natal (RN): EDUFRN, 2001.

7. QUEIROZ, Thiago Augusto Nogueira de. A produção do espaço urbano de Natal-RN: algumas considerações sobre as políticas públicas. Observatorium, v. 2, p. 2-16, 2010.

8. SOUZA FILHO, Newton de. Linhas de transporte na Zona Norte. Natal: Semob, 2015.

9. SANTOS, Milton. Metamorfoses do Espaço Habitado: Fundamentos teóricos e metodológicos da Geografia. 1ํo ed. São Paulo: Hucitec, 1988.

10. SOUZA, Itamar de. Nova História de Natal. Natal: Diário de Natal, 2000. 